\title{
EL NACIMIENTO DE LA ARQUITECTURA BARROCA NOVOHISPANA: UNA INTERPRETACION *
}

MARTHA FERNÁNDEZ

\section{El siglo XVI}

La arquitectura religiosa de la Nueva España tuvo su origen en el momento en que se inició la evangelización del territorio; sin embargo, es un hecho que a lo largo del siglo xvi y espeçialmente durante los primeros años de la conquista, la llegada de artistas europeos al virreinato fue muy precaria. Se conocen nombres como los de Toribio de Alcaraz, Francisco Becerra y Pedro del Toro, pero en general las construcciones se llevaron a cabo bajo la dirección de los frailes mendicantes encargados de llevar a cabo la empresa evangelizadora. Fueron ellos, apoyados siempre por la mano de obra indígena, quienes levantaron sus conventos a lo largo y ancho del territorio novohispano.

Estilísticamente hablando, los modelos de que echaron mano estos frailes para levantar sus construcciones fueron: recuerdos vagos, imprecisos y, en la mayoria de los casos, atemporales de las obras que habían visto en España, y, de manera muy especial, los grabados europeos de formas decorativas, que a menudo no corresponden a obras arquitectónicas. $^{1}$

Todos estos factores: la dirección frailuna, la mano de obra indígena y las fuentes de inspiración que utilizaron, dieron por resultado conven-

* Este texto fue presentado como ponencia en la I Conferencia General de Historia de la Iglesia en América Latina organizada por el Centro de Estudios de la Historia de la Iglesia en América Latina (CEIHLA) del 10 al 13 de octubre de 1984.

En general, el texto es el mismo que conformó la ponencia, sólo que, envista de que el público al que se dirigía entonces no era especializado, en aquella ocasión hube de incluir algunos párrafos de información general que en esta ocasión he preferido suprimir y, en cambio, me ha parecido más conveniente remitir al lector a los textos de autores que se han ocupado de esos temas con mayor profundidad.

Ahora bien, más que un estudio f́ormal, esta presentación viene a ser una nota que tiene tres objetivos básicos:

10. Analizar el papel de los arquitectos en su fenómeno artístico concreto.

20. Analizar el papel de los arquitectos oficiales en ese mismo fenómeno artístico.

3o. Analizar la influencia de los monumentos oficiales en la confirmación de ese fenómeno artístico:

Esto es, que el fin último de esta nota es simplemente aplicar a un caso concreto las ideas que muchos hemos venido manejando sólo a niveles teóricos.

i Jorge Alberto Manrique, "El tr asplante de las formas artísticas españolas a México", en Actas del Tercer Congreso Internacional de Hispanistas, México, El Colegio de México, 1969, p. 573. 
tos monumentales, desde el punto de vista formal, y edificios híbridos, desde el punto de vista estilístico. ${ }^{2}$

Así, la arquitectura conventual mexicana del siglo XVI se caracteriza por la carencia de estilos definidos y unitarios en un solo monumento. El estilo artístico del México de entonces fue la amalgama de estilos y modalidades europeos de diferentes épocas que se incorporaron a las construcciones, las cuales lucen la mezcla de elementos góticos, mudéjares, platerescos y manieristas. El resultado, como he dicho, fue la crea" ción de edificios híbridos o bien de obras tequitqui. ${ }^{3}$

Se debe aclarar, sin embargo, que lo que más importaba a los constructores de estas obras era su eficacia práctica e iconográfica, no la corrección estilística de sus formas.

\section{Las maestrías mayores de arquitectura}

A fines del siglo xvi, se produjeron una serie de fenómenos históricos que dieron por resultado el auge de las ciudades: la sociedad se comenzó a ubicar en los centros urbanos. Las ciudades se impusieron al campo, las catedrales a los conventos y los palacios a las haciendas.

Fue en ese momento, desde las florecientes ciudades, cuando se inició la preocupación real por la falta de buenos arquitectos en la Nueva España, de arquitectos no híbridos, sino formados en una tradición artística concreta, conocedores de sus reglas, de sus alcances y limitaciones, y al tanto de lo que en arquitectura se hacía en Europa.

La información documental revela que esta preocupación partió de las mismas autoridades civiles, en especial de los virreyes. Don Antonio de Mendoza, por ejemplo, hacia 1550 afirmó que "en lo que toca a los

\footnotetext{
${ }^{2}$ Martha Fernández, "El convento novohispano" en Historia Temática de México, México, Salvat Editores, en prensa.

${ }^{3}$ Martha Fernández, "Los estilos del arte conventual", en Historia Temática de México, México, Salvat Editores, en prenisa. Para ampliar la información acerca del arte tequitqui véase: José Moreno Villa, La escultura colonial mexicana, Mẻxico, El Colegio de México, 1942; José Moreno Villa, Lo mexicano en las artes plásticas, México, El Colegio de México, 1948; Constantino Reyes Valerio, El arte indocristiano, México, Instituto Nacional de Antropología e Historia, 1978; Enrique Marco Dorta, "Consideraciones en torno al llamado 'estilo tequitqui"', La dicotomía entre arte culto y arte popular (Coloquio Internacional de Zacatecas), prólogo de Jorge Alberto Manrique, México, Instituto de Investigaciones Estéticas, Universidad Nacional Autónoma de México, 1979 (Estudios de Arte y Estética: 14); Jorge Alberto Manrique, op . cit.; Elisa Vargas Lugo, Las portadas religiosas de México, México, Instituto de Investigaciones Estéticas, Universidad Nacional Autónoma de México, 1969 (Estudios y Fuentes del Arte en México, XXVII); Martha Fernández, "Historia del concepto de 'arte tequitqui"”, Tesis, Facultad de Filosofia y Letras, Universidad Nacional Autónoma de Méxiç, 1976.
} 
edificios de monasterios y obras públicas, ha habido grandes yerros, por no tener quien los atendiese ni supiese dar orden en ellos..."

Por su parte, en 1601, el conde de Monterrey comunicó a Felipe III que

... acá se saben estas artes con poco fundamento de estudios, que aun para juzgar el que sabe o el que no, se vive muy a oscuras...,

y agregó:

... es contra el decoro de tan gran república estar a ciegas en artes $\tan$ principales y que ni en la Universidad haya quien lea los principios de ellas, ni en este pueblo quien las ejecute, no teniendo estas provincias más luz que la de aquí ...

Tan grande era la preocupación del conde de Monterrey que llegó a sugerir al rey que considerara la posibilidad de "... enviar algún grande artífice, aunque fuese con grueso salario..."

Sin embargo, la solución que finalmente se llevó a cabo, fue la que hacia 1550 don Antonio de Mendoza sugirió a don Luis de Velasco en las Instrucciones que le dejó, a saber, que el propio virrey "... mande buscar dos o tres personas que sean buenos oficiales y déles salario en quitas y vacaciones y corregimiento para que anden por toda la tierra visitando las obras y enmendando los defectos que son muchos..."

En concreto, lo que sugirió don Antonio de Mendoza a su sucesor fue la elección de arquitectos de su confianza que se encargaran de dirigir y supervisar la construcción y el mantenimiento de los edificios que se estaban levantando en la Nueva España.

La sugerencia del primer virrey fue aceptada y llevada a ejecución por don Luis de Velasco, quien en 1559 hizo traer de Puebla de los Ángeles al arquitecto español Claudio de Arciniega con el nombramiento de "Maestro Mayor de las Obras de Cantería de la Nueva España"?

${ }^{4}$ Añselmo de la Portilla, Instrucciones que los virreyes de Nueva España dejaron a sus sucesores, 2t, México, Imprenta Ignacio Escalante, 1873, t. I, p. 46.

"Martha Fernández, Arquitectura y gobierno virreinal." los maestros mayores de la ciudad de México. Siglo XVII, presentación de Jorge Alberto Manrique, México, Instituto de Investigaciones Estéticas, Universidad Nacional Autónoma de México, 1985, documento número XVIII del apéndice; apud AGI (Audiencia de México: 24, ramo duplicados, doc 62),

${ }^{6}$ Anselmo de la Portilla, op cit., t. 1, p p. 46-47.

7 Efraín Castro Morales, "Los maestros mayores de la catedral de México" en Artes de México, 182-183, año XXI (México, 1976), p. 139. Martha Fernández, Arquitectura y gobierno virreinal... 
De la historia de las maestrías mayores, me he ocupado en otros trabajos," baste por ahora precisar que siempre fueron otorgadas por las autoridades civiles y eclesiásticas, de manera que pueden considerarse nombramientos o cargos de carácter oficial. Además, como es de suponerse, la primera obligación de los arquitectos designados maestros mayores era la de atender las obras que más importaban a esas autoridades: catedrales, palacios de gobierno, edificios inquisitoriales, obras del Patronato Real, etcétera; o sea, las construcciones de tipo oficial. Por lo tanto, los maestros mayores de arquitectura vienen a ser los arquitectos oficiales del virreinato.

Como se suede deducir fácilmente, bajo tales circunstancias, los maestros mayores alcanzaron un gran prestigio en la Colonia y fueron solicitados incluso por patronos particulares para supervisar, dirigir o dar simplemente el visto bueno a sus propias obras, fueran éstas, casas habitación $\mathrm{u}$ obras religiosas.

Por su parte, los edificios oficiales, por el simple hecho de serlo, ganaron su propio prestigio frente a los demás monumentos; se convirtieron en los modelos artísticos a seguir.

La conjunción de los maestros mayores y las construcciones oficiales viene a ser, desde mi punto de vista, un factor decisivo en el desarrollo de la arquitectura virreinal mexicana.

En esta ocasión, centraré mi atención en mostrar cómo, bajo este enfoque, me explico un fenómeno artístico en particular: el nacimiento de la arquitectura barroca.

Ahora bien, es un hecho que el arte barroco hizo su aparición en cada una de las provincias y ciudades de la Nueva España en circunstancias particulares y en un tiempo histórico específico, de manera que es imposible que en esta breve exposición analice los hechos históricos que dieron lugar al nacimiento de la arquitectura barroca en todo el territorio de la Nueva España, por lo que he decidido ocuparme hoy solamente del centro político, social, cultural y artístico del virreinato: la ciudad de México.

\footnotetext{
${ }^{8}$ Martha Fer nández, Arquitectura y gobierno virreinal . ., " "Los maestros mayores de la ciudad de México" en Historia del Arte Mexicano, t. IV, Salvat Editor es (México, 1982); "Los maestros mayores de arquitectura en la Nueva España ante las autoridades virreinales", VI Reunión de Historiadores Mexicanos y Norteamericanos, celebrada en Chicago, del 8 al 12 de septiembre de 1981, en prensa.
} 


\section{El nacimiento de la arquitectura barroca en la ciudad de México}

A partir de que recibió el nombramiento de maestro mayor, Claudio de Arciniega comenzó a adquirir una gran importancia: él no sólo demostró ser un buen arquitecto en el sentido de que sus obras no tenían "yerros", sino que además resultó ser un conocedor del arte manierista, estilo vigente en la Europa de aquel tiempo.

A él se debió el primer monumento arquitectónico manierista de la Nueva España: el Túmulo Imperial de Carlos V que levantó en 1559 en la capilla de San José de los Naturales; ${ }^{9}$ y a él se debió también, la planta manierista de la actual catedral metropolitana. ${ }^{10}$

Definir el manierismo es una empresa difícil y escapa a límites de este trabajo baste decir que es un estilo que abandona el abigarramiento de formas y tiene reglas muy precisas. Tanto que con él surgieron los tratados de arquitectura en los que codificaton esas reglas autores como Alberti y Serlio y se reutilizaron los de autores como Vitruvio, pero en términos generales podemos decir que es un arte culto, fundamentalmente citadino y secular. Utiliza el repertorio de formas inspiradas en la antigüedad clásica con mayor cuidado y conocimiento de causa, tratando de seguir los tratados de arquitectura que condificaban los principios del arte clásico."

El manierismo se adoptó y se difundió en toda la Nueva España. Su arraigo fue tal, que aun en pleno siglo xvin en los momentos de mayor esplendor barroco, permanecieron incólumes algunos elementos de la arquitectura manierista, sin embargo, el manierismo, como estilo unitario, alcanzaría los años cuarenta-cincuenta del siglo xvII. ${ }^{12}$

En efecto, hacia mediados del segundo siglo virreinal se comenzaron a manifestar de manera clara algunos cambios en la arquitectura. Surgieron obras como las portadas del templo de Santiago Tlatelolco, de las cuales Diego Angulo opina que:

su autor parece apartarse de sus contemporáneos, pues mientras conserva en la parte inferior el estilo de fines del siglo Xvi .... en la parte

\footnotetext{
9 Jorge Alberto Manrique, "Reflexiones sobre el manier ismo en México", en Anales del Instituto de Investigaciones Estéticas, X, 40 (México, 1971), p. 26.

${ }^{10}$ Manuel Toussaint, La catedral de México y el Sagrario Metropolitano. Su historia, su tesoro, su arte, prólogo y notas por Gonzalo Obregón, 2a ed., México,Editorial Porrúa, 1973, p p. 31-32.

${ }^{11}$ Véase Jorge Alberto Manrique, "Reflexiones sobre el manierismo en México."

12 Ibidem, p. 26.
} 
superior tal vez se deja influir por el estilo de los ensambladores de retablos. ${ }^{13}$

Asimismo, hacia 1655 se levantaron las portadas del convento de monjas de la Concepción, las cuales, enmedio de su esquema manierista, presentan, como dice Elisa Vargas Lugo, ". . cierta riqueza barroca..." manifiesta especialmente en su vano de ingreso, pues "...debajo del medio punto luce un arco semiexagonal y luego, sus enjutas y frisos se rellenan con relieves fitomorfos..."14

Entre los arquitectos innovadores de ese tiempo podemos mencionar, a manera de ejemplo, a Diego de los Santos y Ávila, maestro mayor del Santo Tribunal de la Inquisición a partir de $1657 . .^{15}$ De sus obras documentadas, la más importante para conocer los ideales artísticos que lo animaron es el proyecto que presentó en 1659 para construir, precisamente, la capilla del Santo Oficio. ${ }^{16} \mathrm{El}$ dibujo de la portada que planeaba levantar para ella y que por desgracia nunca se construyó, es muy interesante, pues nos muestra una obra que acertadamente Francisco de la Maza calificó de "suave barroquismo". ${ }^{17}$ Los frontones rotos y las almohadillas de las pilastras y de las jambas, imprimen a esta portada dos características barrocas básicas: la ascensión y el claroscuro.

Pero contemporáneos a Diego de los Santos y a los autores de las portadas de la Concepción y Santiago Tlatelolco, existieron otros arquitectos de formación manierista. Entre ellos, los más importantes fueron Luis Gómez de Trasmonte y Rodrigo Díaz de Aguilera, nombrados, respectivamente, maestro mayor y aparejador mayor de la catedral de México el 2 de febrero de $1656 .{ }^{18}$

${ }^{13}$ Diego Angulo Iñiguez y Enrique Marco Dorta, Historia del arte hispanoamericano, $3 \mathrm{t}$., Salvat Editôies, $1945-50, t, 11, p$ p. 12-13.

${ }^{14}$ Elisa Vargas Lugo, op. cit, p. 71.

${ }^{15}$ Martha Fernández, Arquitectura y gobierno virreinal. . .; apud. AGN (Real Fisco: 115, doc. 1, fol. 1 r.).

${ }^{16}$ Francisco de la Maza, "El proyecto para la capilla de la Inquisición" en Anales del Instituto de Investigaciones Estéticas, III, 12 (México, 1945); Francisco de la Maza: El palacio de la Inquisición (Escuela Nacional de Medicina), México, Instituto de Investigaciones Estéticas, Universidad Nacional Autónoma de México, 1951 (Ediciones del IV Centenario de la Universidad de México: IX), p 21-23; Martha Fer nández, Arquitectura y gobierno virreinal...

${ }^{17}$ Francisco de la Maza, El palacio de ia Inquisición, p p. 22-23

${ }^{18}$ Heinrich Berlin, "Artífices de la catedral de México (Investigación en el Archivo General de la Nación)", en Anales del Instituto de Investigaciones Estéticas, III, 11 (México, 1944), p. 30, apud: AGN (Duplicado de Reales Cédulas." 25, doc. 210, fol 83 vto..); Palacio Nacional, México, Secretaría de Obras Públicas, Unidad Editorial, 1976, p. 300; Diego Angulo Iñiguez, op cit., t. II, p. 8; Efraín Castro Morales, op. cit., p. 141; Richard Boyer, "La ciudad de México en 1628. La visión de Juan Gómez de Trasmonte", en Historia Mexicana, XXIX, 3, El Colegio de México (México, enero-marzo, 1980), p. 456; Martha Fernández, Arquitectura y gobierno virreinal..., apud: AGI (Audiencia de México 2708). 
El sentido artístico de ambos arquitectos se manifiesta principalmente en tres obras: las anotaciones que hizo Rodrigo Díaz de Aguilera a una edición del tratado de arquitectura de Vitruvio; las críticas que Gómez de Trasmonte y Díaz de Aguilera hicieron al proyecto del cimborrio de la catedral de Valladolid realizado por el arquitecto Vicencio Barroso de la Escayola; y, la más importante: la portada del Perdón de la catedral de México.

Los comentarios de Rodrigo Díaz de Aguilera al tratado de Vitruvio fueron escritos en 1668, a ellos dedicó un artículo Manuel Toussaint. De todos, los más elocuentes para el objetivo que perseguimos, son los siguientes:

Los que se contentaron con sólo la teórica, sin la experiencia de la práctica, sólo han conseguido la sombra de la arquitectura. Y sólo se puede llamar arquitecto el que, en lo teórico y práctico ha llegado a ser perfecto...

Es simetría una ordenación en las partes, con tal disposición que cada una corresponda con el todo y el todo con sus pattes...

Tetrástylos es y quiere decir de cuatro colunas, y aunque dice que la frente para este orden se parta en 27 partes, parece estar errado, y Sebastián Serlio en el libro 4 que trata de la orden doria a fojas 22 trata deste texto y la distribución destas columnaciones, en sus espacios altos.

En opinión de Toussaint:

Maese Rodrigo entendía bien su latín, pero además le interesaba mucho su oficio. Por eso escribe anotaciones de su puño y letra en las márgenes del libro. No son tantas como desearíamos, mas nos indican un anhelo, una ansia de comprender el texto del maestro y sus anotadores... ${ }^{19}$

No obstante, creo que el interés de don Rodrigo iba más allá: no sólo se preocupaba por desempeñar bien el oficio que amaba, sino que buscaba llegar a su "perfección", y lo más interesante es que en 1668 todavía encontraba esa perfección en los tratados de arquitectura, en los mismos modelos en los que la encontraron los artistas manieristas.

Luis Gómez de Trasmonte compartió con Rodrigo Díaz de Aguilera

\footnotetext{
${ }^{19}$ Manuel Toussaint, "Vitruvio interpretado por un arquitecto de Nueva España en el siglo XVII" en Anales del Instituto de Investigaciones Estéticas, V, 18 (México, 1950), p p. 85-88.
} 
ese mismo ideal estético, de manera que cuando, en 1660, ambos maestros fueron requeridos para emitir su opinión en relación al proyecto elaborado por Vicencio Barroso de la Escayola para cerrar el cimborrio de la catedral de Morelia, opinaron que era una solución viciosa y

... reprobada de los autores y particularmente de Sebastián Celi [Serlio] en su tercer libro de antiguiedades, en la foja veinte y tres y la razón es porque levanta con el banco señalado con la cruz repartida en su circunferencia once varas de alto, según muestra el pitipie de la planta, y sobre este banco carga la media naranja, con que queda desamparada la obra y con poca seguridad, principalmente en este Reino, por los accidentes de temblores y terremotos ...20

Su obra más importante, sin embargo, la realizaron en su catedral: la portada del Perdón de la catedral de México.

En un informe que presentaron Gómez de Trasmonte y Díaz de Aguilera el año de 1672 acerca de los trabajos que se habían llevado a cabo en el templo durante el gobierno del virrey marqués de Mancera, ambos arquitectos declararon que esta portada la tenían proyectada en tres cuerpos:

... el primero dórico, el segundo jónico y el tercero compósito, siguiendo toda su obra de la piedra que llaman de chiluca y alguna de la cantera de los Remedios, taraceada toda de mármol o piedra blanca que llaman de villerías; obra verdaderamente real, así por la materia como por la forma en su arquitectura y digna de tan suntuoso templo... ${ }^{21}$

Trabajando juntos, Luis Gómez de Trasmonte y Rodrigo Díaz de Aguilera levantaron los dos primeros cuerpos de la portada: el primero, estaba terminado en 1672, y el segundo, parece que en 1678; de acuerdo al proyecto que he expuesto, o sea, el primer cuerpo dórico y el segundo jónico. El segundo cuerpo debió ser modificado entre 1684 y 1689 por Cristóbal de Medina, sin embargo, el primero, aún se conserva como lo dejaron sus autores. ${ }^{22}$

\footnotetext{
${ }^{20}$ Ana Maria Liaño Pacheco, "La catedral de Morelia" en Arte en América y Filipinas, t. II, Universidad de Sevilla, 1949, p. 102, apud. AGI (Audiencia de México: 1052); Martha Fernández: Arquitectura y gobierno virreinal ..., Apud: doc cit.

${ }^{21}$ Martha Fernández, Arquitectura y gobierno virreinal ..., documento numero XX del apéndice, apud: AGI (Audiencia de México: 46, ramo 4, doc. 41-A)

${ }^{22}$ Martha Fernández, "Algunas reflexiones en torno a las portadas de la catedral de México", en Anales del Instituto de Investigaciones Estéticas, 53 (México, 1985).
} 
DOI: http://dx.doi.org/10.22201/iie.18703062e.1986.56.1308

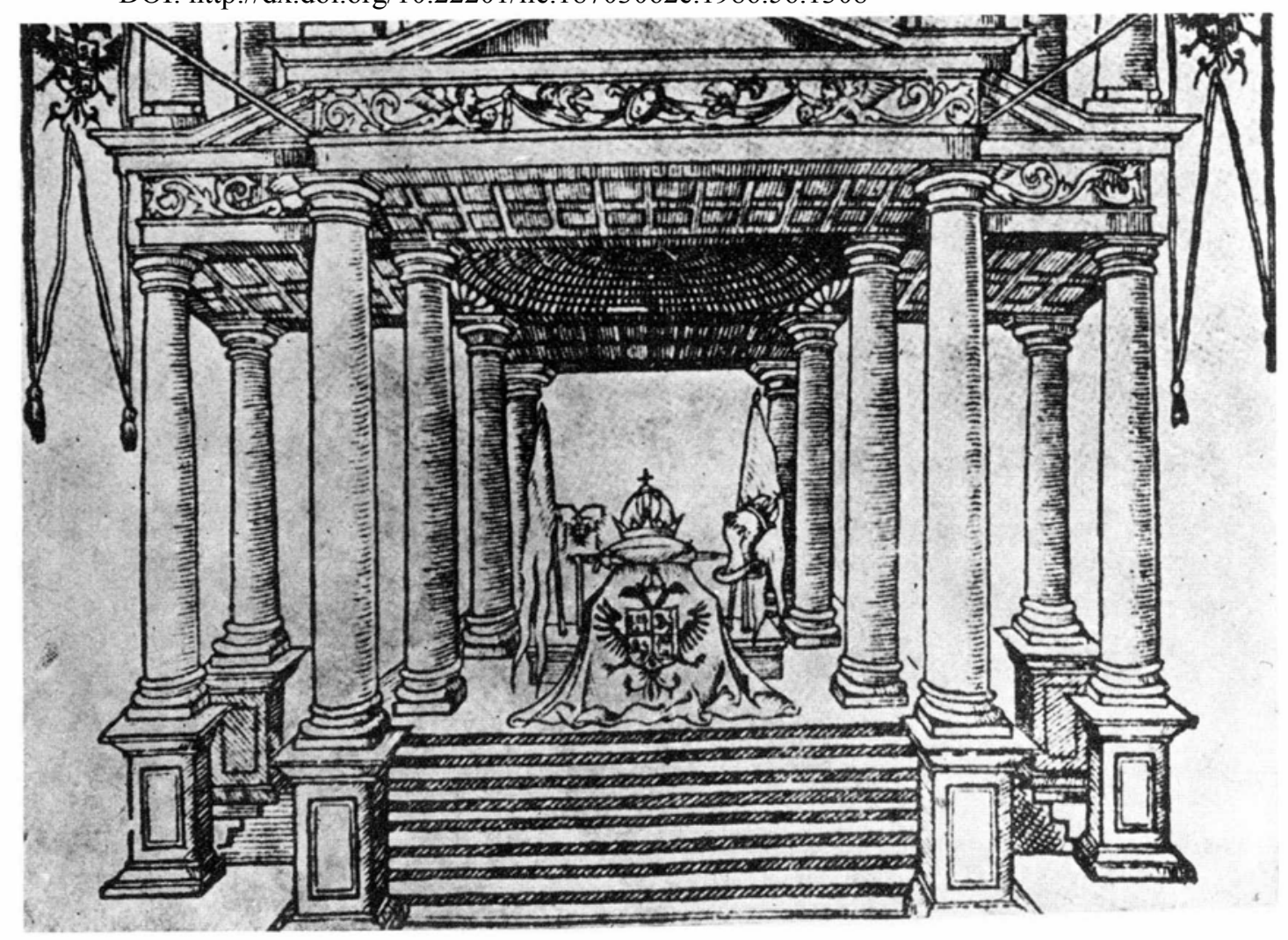

Figura 1. Túmulo Imperial de Carlos V. Obra de Claudio de Arciniega (1559). Foto I.I.E. 
DOI: http://dx.doi.org/10.22201/iie.18703062e.1986.56.1308

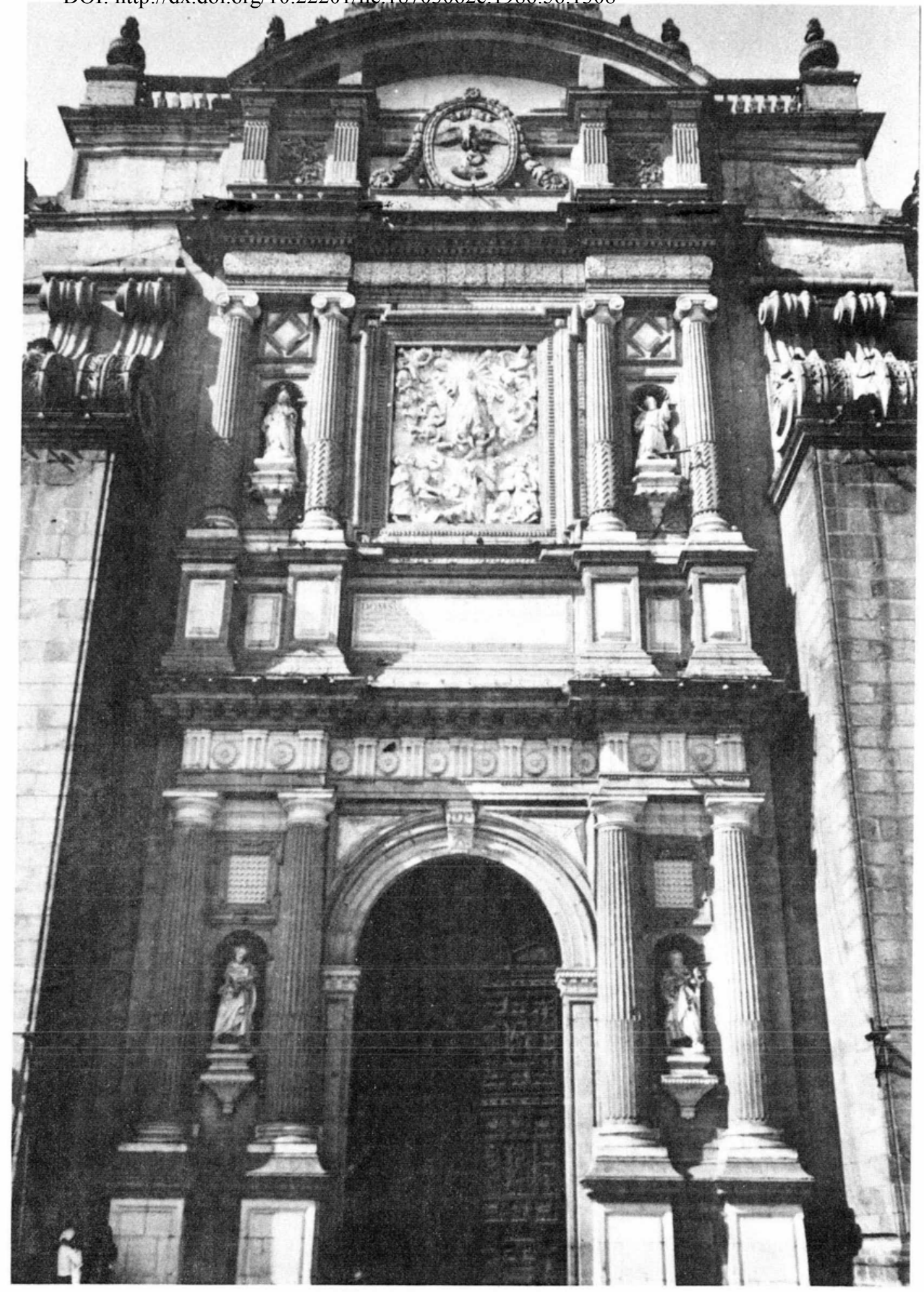

Figura 2. Portada del Perdón de la catedral de México. El primer cuerpo fue concluido en 1672 por Luis Gómez de Trasmonte y Rodrigo Díaz de Aguilera. El segundo cuerpo fue modificado entre 1684 y 1689 por Cristóbal de Medina. Foto I.I.E. 


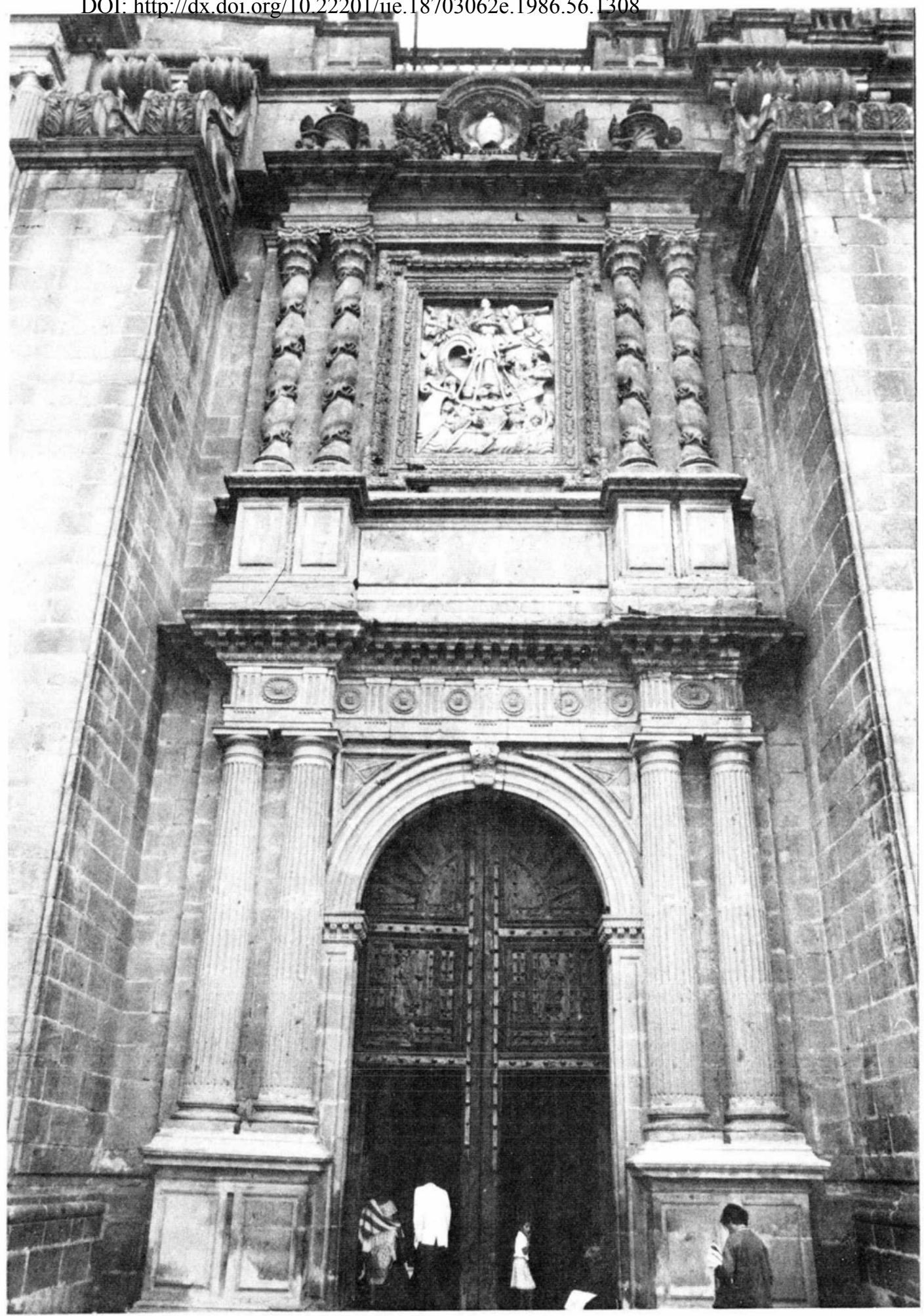

Figura 3. Portada procesional poniente de la catedral de México. El primer cuerpo debió levantarse entre 1682 y 1684 por Juan Montero. El segundo cuerpo fue construido entre 1684 y 1689 por Cristóbal de Medina. Foto: Regina Hernández, I.I.E. 


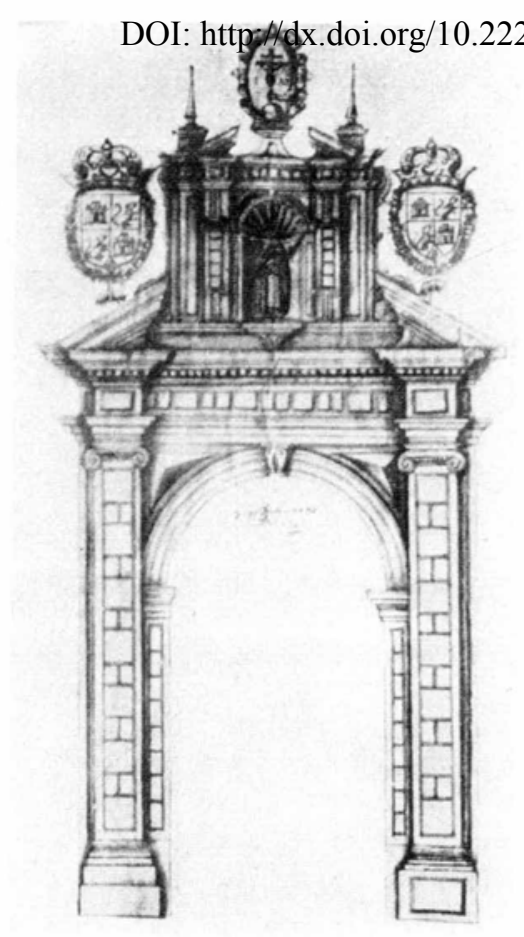

Figura 4. Proyecto de Diego de los Santos y Ávila para levantar la portada de la capilla de la Inquisición presentado en 1659. Foto I.I.E.

Figura 5. Portadas del templo de Santa Teresa la Antigua, construídas entre 1684 y 1689 por Cristóbal de Medina. Foto I.I.E.

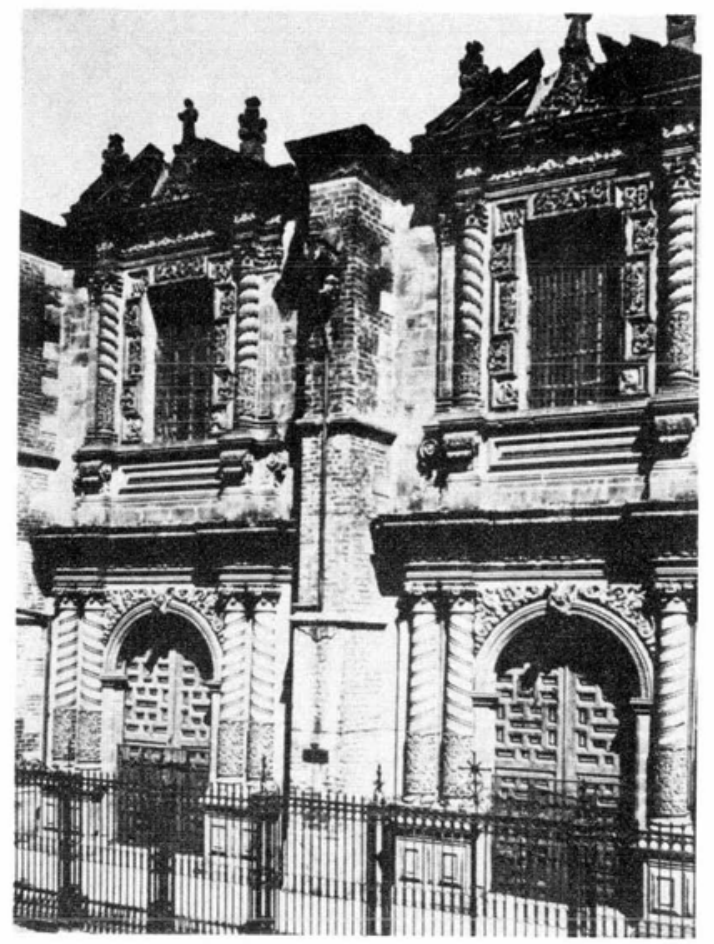


Sus características son muy claras: vano de medio punto, moldurado, con la clave señalada por una ménsula; columnas pareadas de orden dórico, con estrías y contraestrías; el friso luce los tradicionales triglifos y metopas, y la cornisa recta con canecillos. Es una obra que responde al gusto artístico de los tratadistas, al gusto de Luis Gómez de Trasmonte y Rodrigo Díaz de Aguilera. ${ }^{23}$

¿Cómo explicar que después de la aparición de abras como las portadas del templo de la Concepción en 1655, y el proyecto para levantar la portada de la capilla de la Inquisición en 1659, en plena catedral de México se levante, en 1672, una portada manierista?

Me parece que la respuesta es clara: desde mediados del siglo xvII se produjo una tensión entre los arquitectos de formación manierista y los jóvenes innovadores. Ahora bien, como hemos visto, existieron maestros mayores que pertenecieron a ese grupo de jóvenes innovadores, como Diego de los Santos -maestro mayor de la Inquisición-; y maestros mayores que conservaron la tradición menierista, como Luis Gómez de Trasmonte - maestro mayor de la catedral de México-. Veamos ahora la influencia decisiva que tuvieron los mayores de la catedral en el desarrollo de la arquitectura virreinal, y la influencia de la propia catedral como modelo artístico a seguir. Para ello, recurriremos a otro arquitecto: Juan Montero de Espinosa.

Juan Montero fue maestro mayor del Santo Tribunal de la Inquisisición $^{24}$ y aparejador mayor de la catedral de México, a partir del año

${ }^{23}$ Manuel González Galván, "Modalidades del barroco mexicano" en Anales del Instituto de Investigaciones Estéticas, VIII, 30 (México, 1961). El arquitecto califica a esta portada catedralicia como del "barroco purista". En su opinión: "El barroco purista es modalidad que llamamos así puesto que se reconoce en que, pese a los alardes ornamentales permitidos en los elementos constructivos que complementan o rodean columnas y pilastras, éstas permanecen con sus básicas formas clásicas y estáticas, con sus fustes estriados con nitidez y en el caso de las columnas, hasta su curva o gálibo limpiamente trazado a partir del primer tercio . Es el barroco consciente de sus posibilidades, pero respetuoso de la esencial tradición arquitectónica como si dejara patente con esta actitud, la firmeza de sus bases clásicas. ... En un principio el barroco es tán respetuoso de la verdad constructiva, que sólo se atreve a distorsionar y poner en movimiento los eiementos sustentados o secundarios de la arquitectura.... pero sin modificar en nada los que representan el equilibrio y estabilidad de la obra como son: columnas, pilastras y pedestales".

En el caso de la portada catedralicia que nos ocupa, no existió esa intención o esa conciencia barroca: se concibió manierista y se modificó después, ya en pleno uso de las facultades del barroco

${ }^{24}$ Martha Fernández, Arquitectura y gobierno virreinal. ., Apud: AGN (Bienes Nacionales: 381, doc. 18, fol 42 r.), dato del I I E, Francisco de la Maza El Palacio de la Inquisición, p. 24; Martha Fernández, "El inventario de bienes de un artista novohispano: el arquitecto Juan Montero", en Anales del Instituto de Investigaciones Estéticas, 54 (México, 1985), apud" doc "cit." Palacio Nacional, p. 300. 
de $1678^{25}$ en que murió Rodrigo Díaz de Aguilera. Además de arquitecto, Montero fue escultor y ensamblador, ${ }^{26}$ de manera que, amén de construir edificios, también levantó retablos.

Por desgracia, no se conserva ninguno de sus retablos, pero las descripciones de sus proyectos, insertas en los contratos para realizarlos, son bastante elocuentes en relación a sus ideales estéticos, verbigracia, el que concertó el 16 de julio de 1676 con el convento de Santa María de Gracia de Guadalajara. En él, Montero afirma que el retablo ten. dría en el primer cuerpo "...cuatro columnas tortuosas que llaman salomónicas, que han de ir todas revestidas de talla de todo relieve". ${ }^{27}$ Es decir, que Juan Montero, al igual que Diego de los Santos, era un artista barroco; sin embargo, en la obra de la catedral, no lo manifiesta.

Como he dicho, en 1678 Juan Montero fue electo aparejador mayor de la catedral de México. Por razones de enfermedad, la actividad del maestro mayor, Luis Gómez de Trasmonte, decayó mucho, de manera que prácticamente Juan Montero se hizo cargo de la obra de la catedral de 1678 a 1684 . En ese tiempo, al parecer construyó el primer cuerpo de las portadas procesionales e inició el tercero de la portada del Perdón. ${ }^{28}$

Como se puede apreciar, en las portadas procesionales, Juan Montero no modificó en nada el esquema manierista de la portada del Perdón. En este caso, podemos pensar que la necesidad de mantener el equilibrio con la portada central, obligó a Montero a seguir los mismos lineamientos. Pero, ¿por qué no buscó una fórmula más novedosa? Es seguro que conociendo los principios artísticos del manierismo y del barroco, no le hubiera sido difícil encontrar la solución; como, según vermos, otro artista la encontró.

El problema, creo, está más bien en la presencia del maestro mayor de la obra: aunque enfermo, Luis Gómez de Trasmonte aún vivía, y no parece que hubiera sido fácil para nadie, que bajo su maestría mayor, se propusieran cambios estilísticos importantes en su catedral.

\footnotetext{
${ }^{25}$ Martha Fernández, Arquitectura y gobierno virreinal ..., apud AGI (Audiencia de México. 2708) y $\operatorname{ASM}$ (Libro de difuntos españoles, años 1671-1680, fol 251 vto.). Efrán Castro Morales, "Juan Monteros ensamblador y arquitecto novohispano del siglo XVII" en Boletín Monumentos Históricos, Instituto Nacional de Antropología e Historia 6 (México, 1981), p. 18. Martha Fernández, "El inventario de bienes de un artista novohispano...", apud docs. cit.

${ }^{26}$ Martha Fernández, Arquitectura y gobierno virreinal ..., apud : AGI (Audiencia de México: 2708) y AN (Notario Pedro Deza Ulloa, v. III, lib. III, fol 209 r-210 r.). Efraín Castro Morales, "Juan Montero, ensamblador y arquitecto novohispano del siglo XVII" p. 11-17 apud: docs. del AN Martha Fernández; "El inventario de bienes de un artista novohispano .."

${ }^{27}$ Efraín Castro Morales, "Juan Montero, ensamblador y arquitecto novohispano del siglo XVII", p. 13, apud" AN (Notario Bernabé Sarmiento de Vera, años 1676-78, fol 69).

${ }^{28}$ Martha Fernández, "Algunas reflexiones en tor no a las portadas de la catedral de México".
} 
Luis Gómez de Trasmonte murió el 28 de septiembre de $1684^{2 ! 3}$ y el 3 de octubre del mismo año, el arquitecto Cristóbal de Medina Vargas Machuca fue nombrado maestro mayor de la catedral de México. ${ }^{3+}$

Fuera ya de la influencia de uno de los artistas manieristas más importantes de la Nueva España, Cristóbal de Medina encontró la fórmula para sacar el arte barroco al exterior: de los retablos a las fachadas, y lo hizo precisamente en la catedral de México. Entre 1684 y 1689 levantó el segundo cuerpo de las portadas procesionales y construyó las portadas del crucero, pero incluyó un elemento arquitectónico barroco: las columnas salomónicas. ${ }^{31}$

A partir de ese momento, la arquitectura barroca se generalizó: la adopción de este estilo en la catedral de México, el edificio más imimportante de la Nueva España, originó el triunfo de la arquitectura barroca en la ciudad de México, prueba de ello es que, entre 1684 y 1689 , o sea contemporáneas a las portadas catedralicias, el propio Cristóbal de Medina levantó otras dos fachadas salomónicas: las del templo de Santa Teresa la Antigua y la de la iglesia de San Agustín. ${ }^{32}$

\section{Conclusiones}

De lo expuesto, cabe insistir en dos hechos: en primer lugar, la importancia artística de los maestros mayores; y en segundo lugar, la importancia de los maestros mayores de las catedrales en el desarrollo del arte virreinal.

${ }^{29}$ Ibidem, Martha Fernández, Arquitectura y gobierno virreinal ..., documento número VI del apéndice, apud ASM (Libro de difuntos españoles, años 1681-1686 fol. 213 vto.)

${ }^{30}$ Martha Fernández, Arquitectura y gobierno virreinal ..., Apud AGI (Audiencia de MéxiCo." 163, ramo 2, doc. 28). Martha Fernández.. "Algunas reflexiones en torno a las portadas de la catedral de México", Apud doc cit. Heinrich Berlin, op. cit., p. 32, apud. AGN (Duplicado de Reales Cédulas: 28, fol 234). Efraín Castro Morales, "Los maestros mayores de la catedral de México", p. 142. Palacio Nacional, p. 300 . Efraín Castro Morales, "Juan Montero, ensamulador y arquitecto novohispano del siglo XVII", p. 26.

31 Martha Fernández, "Algunas reflexiones en torno a las portadas de la catedral de México".

32 Martha Fernández, Arquitectura y gobiemo virreinal ..., apud. AGI (Audiencia de México: 163, ramo 2, doc 28) y AN (Notario José de Anaya, año de 1678, fol 209), deto del IIE La obra, la formación y el estilo ar tístico de Cristóbal de Medina serán analizados con mucha mayor profundidad en un estudio que preparo sobre este arquitecto para el Instituto de Investigaciones Estéticas de la UNAM.

Abreviaturas: AGI: Archivo laboral de Indios de Sevilla, España. AGN: Archivo laboral de la Nación AN: Archivo de Notarias de la ciudad de México. ASM: Archivo del Sagrario Metropolitano de México 
Ciertamente, en la conformación de los estilos virreinales influyeron muchos factores, como el gusto de la sociedad de entonces, los vaivenes económicos, la política de cada virrey en materia de construcciones civiles, la política de cada arzobispo en materia de construcciones religiosas, etcétera; así como los modelos importados de Europa, los cambios internos de los estilos...

Sin embargo, creo que uno de los elementos decisivos en cada transformación estilística, tanto en la capital, como en todas las provincias de la Nueva España, fueron los autores: su formación, su trayectoria artística, sus lazos de parentesco y de amistad con otros artistas, etcétera, contribuyen a comprender mucho más cabalmente la historia del arte colonial mexicano.

Lo que propongo, en concreto, es una interpretación del arte virreinal que además tome en cuenta la creatividad de sus autores. 